\title{
Complementary targeting of liposomes to IL-1? and TNF-? activated endothelial cells via the transient expression of VCAM1 and E-selectin
}

\section{Citation}

Gunawan, Rico C., Dariela Almeda, and Debra T. Auguste. 2011. “Complementary Targeting of Liposomes to IL-1? and TNF-? Activated Endothelial Cells via the Transient Expression of VCAM1 and E-Selectin." Biomaterials 32 (36) (December): 9848-9853. doi:10.1016/ j.biomaterials.2011.08.093.

\section{Published Version}

doi:10.1016/j.biomaterials.2011.08.093

\section{Permanent link}

http://nrs.harvard.edu/urn-3:HUL.InstRepos:25757190

\section{Terms of Use}

This article was downloaded from Harvard University's DASH repository, and is made available under the terms and conditions applicable to Other Posted Material, as set forth at http:// nrs.harvard.edu/urn-3:HUL.InstRepos:dash.current.terms-of-use\#LAA

\section{Share Your Story}

The Harvard community has made this article openly available.

Please share how this access benefits you. Submit a story.

Accessibility 


\section{Elsevier Editorial System(tm) for Biomaterials Manuscript Draft}

Manuscript Number:

Title: Complementary Targeting of Liposomes to IL- $1 \alpha$ and TNF- $\alpha$ Activated Endothelial Cells via the Transient Expression of VCAM1 and E-selectin

Article Type: FLA Original Research

Section/Category: Biomaterials for the Delivery of Drugs, Genes, Vaccines and Active Biomolecules (BDGV)

Keywords: liposome; cell adhesion molecule; endocytosis; E-selectin; VCAM1; IL-1 $\alpha$; TNF- $\alpha$; transient; complementary.

Corresponding Author: Dr. Debra T Auguste, PhD

Corresponding Author's Institution: Harvard University

First Author: Rico C Gunawan, PhD

Order of Authors: Rico C Gunawan, PhD; Dariela Almeda, S.M.; Debra T Auguste, PhD

Abstract: Inflammation is in part defined by the transient upregulation of cell adhesion molecules on the surface of endothelial cells (ECs) in response to cytokines. We hypothesized that liposomes with a complementary surface presentation of antibodies to the pattern of molecules on the EC surface may enhance targeting. We quantified the expression of vascular cell adhesion molecule-1 (VCAM1) and endothelial leukocyte cell adhesion molecule-1 (E-selectin) on ECs upon exposure to either tumor necrosis factor- $\alpha$ (TNF- $\alpha$ ) or interleukin- $1 \alpha$ (IL-1 $\alpha$ ) as a function of time. Liposomes, composed of 95 mol\% dioleoyl phosphatidylcholine (DOPC) and 5 mol\% dodecanyl phosphatidylethanolamine (N-dodPE), were prepared by conjugating different molar ratios of antibodies against VCAM1 (aVCAM1) and E-selectin (aE-selectin). Increased binding was observed when immunoliposomes complemented the presentation of VCAM1:E-selectin expressed on TNF- $\alpha$ activated ECs. The 1:1 aVCAM1:aE-selectin liposomes had maximal binding at both 6 and $24 \mathrm{~h}$ on IL-1 $\alpha$ activated ECs due to differences in molecular organization. The results demonstrate that liposomes targeting to inflamed endothelium may be optimized by exploiting the dynamic expression of VCAM1 and E-selectin on the EC surface. 
1

2

3

4

5

6

7

8

\section{Complementary Targeting of Liposomes to IL- $1 \alpha$ and TNF- $\alpha$}

\author{
Activated Endothelial Cells via the Transient Expression of VCAM1 \\ and E-selectin
}

Rico C. Gunawan, Dariela Almeda, and Debra T. Auguste*

\begin{abstract}
School of Engineering and Applied Sciences
\end{abstract}
Harvard University

Cambridge, MA 02138

* Corresponding author:

29 Oxford St.

Cambridge, MA 02138

Phone: 617-384-7980

Fax: 617-495-9837

E-mail: auguste@ seas.harvard.edu. 


\begin{abstract}
Inflammation is in part defined by the transient upregulation of cell adhesion molecules on the surface of endothelial cells (ECs) in response to cytokines. We hypothesized that liposomes with a complementary surface presentation of antibodies to the pattern of molecules on the EC surface may enhance targeting. We quantified the expression of vascular cell adhesion molecule-1 (VCAM1) and endothelial leukocyte cell adhesion molecule-1 (E-selectin) on ECs upon exposure to either tumor necrosis factor- $\alpha$ (TNF- $\alpha$ ) or interleukin-1 $\alpha(\mathrm{IL}-1 \alpha)$ as a function of time. Liposomes, composed of $95 \mathrm{~mol} \%$ dioleoyl phosphatidylcholine (DOPC) and 5 mol\% dodecanyl phosphatidylethanolamine (N-dod-PE), were prepared by conjugating different molar ratios of antibodies against VCAM1 (aVCAM1) and E-selectin (aE-selectin). Increased binding was observed when immunoliposomes complemented the presentation of VCAM1:E-selectin expressed on TNF- $\alpha$ activated ECs. The 1:1 aVCAM1:aE-selectin liposomes had maximal binding at both 6 and 24 h on IL-1 $\alpha$ activated ECs due to differences in molecular organization. The results demonstrate that liposomes targeting to inflamed endothelium may be optimized by exploiting the dynamic expression of VCAM1 and E-selectin on the EC surface.
\end{abstract}

\title{
Keywords
}

liposome, inflammation, endothelial cell, E-selectin, VCAM1, transient 


\section{Introduction}

The transient expression of cell adhesion molecules on endothelial cells (ECs) presents a targeting opportunity for inflamed endothelium [1-3]. Intercellular cell adhesion molecule-1 (ICAM1), endothelial leukocyte adhesion molecule-1 (E-selectin), and vascular cell adhesion molecule-1 (VCAM1) are upregulated on ECs upon activation with inflammatory cytokines [46]. Each of these molecules has been investigated for targeting [7-9]; however, no binding studies have correlated the ratio of antibodies on drug delivery vehicles with the presentation of target molecules on ECs.

Targeting multiple, transiently-upregulated cell adhesion molecules on ECs may amplify binding specificity and cellular uptake of drug delivery vehicles. Microbubble contrast agents conjugated with dual targeting antibodies against VCAM1 and P-selectin bound almost twice as effectively as single-targeting microbubbles [10]. Similarly, the adhesion of microspheres bearing antibodies against ICAM1 (aICAM1) and sialyl Lewis ${ }^{\mathrm{x}}$, a selectin ligand, was dependent on the concentration of both ligands $[11,12]$. Our previous reports also demonstrated that the antibody ratio (aICAM1:aE-selectin) and lipid mobility influenced cellular binding [13].

These observations, however, did not account for the fact that the cell surface is spatiotemporally dynamic. Cell adhesion molecules, such as E-selectin and ICAM1, have been reported to cluster following their engagement in a cytokine or shear-induced response [14]. Clustering of ICAM1 and E-selectin in lipid raft microdomains is required for subsequent cell signaling and gene expression $[15,16]$. Binding of liposomes, targeted to ICAM1 and E-selectin, was reduced to the non-specific level when lipid raft formation was inhibited by addition of a cholesterol chelation agent, methyl- $\beta$-cyclodextrin. [17]. These reports clearly demonstrate the importance of molecular organization on the EC surface in liposome targeting. 
In addition to clustering, the expression of cell adhesion molecules on ECs changes temporally after exposure to cytokines. Several studies have reported the time-course expression of cell adhesion molecules in response to different inflammatory cytokines. Scholz et al. showed that interleukin-1 $\beta$ (IL-1 $\beta$ )-induced VCAM1 and E-selectin expression regressed after $8 \mathrm{~h}$ while ICAM1 was maintained for $72 \mathrm{~h}$ [18]. With IL-1 $\alpha$, E-selectin expression peaked at $6 \mathrm{~h}$ whereas platelet endothelial cell adhesion molecule-1 (PECAM1) reached a plateau after $12 \mathrm{~h}$ [19]. The expression trend for each cell adhesion molecule corresponds to the inflammatory response, where they mediate neutrophil rolling, adhesion, arrest and transmigration [20].

Changes in the endothelial phenotype may be important in the design of drug delivery vehicles that target the endothelium. Targeting of drug delivery vehicles to inflamed ECs may be tailored to the latent stage of the immune response, resulting in consistent delivery of therapeutic agents at the target site (Figure 1).

In this report, we characterized the expression of VCAM1 and E-selectin as a function of time in response to IL-1 $\alpha$ and TNF- $\alpha$. Liposomes were modified with different molar ratios of aVCAM1:aE-selectin to evaluate optimum binding to activated ECs as a function of time. Drug delivery vehicles designed to target inflamed endothelium may benefit from understanding the temporal dynamics of molecules expressed on the EC surface. 


\section{Experimental Methods}

\section{Materials}

1,2-dioleoyl-sn-glycero-3-phosphoethanolamine-N-dodecanyl (N-dod-PE) and 1,2dioleoyl-sn-glycero-3-phosphocholine (DOPC) were purchased from Avanti Polar Lipids (Alabaster, AL). Human recombinant interleukin-1 $\alpha$ (IL-1 $\alpha)$, mouse anti-human VCAM1 (aVCAM1), mouse anti-human E-selectin (aE-selectin) monoclonal antibodies (mAbs), and $\operatorname{IgG}_{1}$ isotype $(\mathrm{mAb})$ were purchased from R\&D Systems (Minneapolis, MN). N-ethyl-N'-(3dimethylaminopropyl)carbodiimide (EDC), N-hydroxysuccinimide (NHS), bovine serum albumin (BSA), human recombinant tumor necrosis factor- $\alpha$ (TNF- $\alpha$ ), rhodamine-B isothiocyanate-conjugated dextran (10 kDa MW), ammonium molybdate, ascorbic acid, anhydrous dimethyl sulfoxide (DMSO), and ethanol (EtOH) were purchased from Sigma (St. Louis, MO). Formaldehyde was obtained from EMD Chemicals, Inc. (Gibbstown, NJ). Fluorescein isothiocyanate (FITC)-conjugated goat anti-mouse (FITC)-conjugated mouse anti-rat, tetramethyl rhodamine isothio-cyanate (TRITC)-conjugated rabbit anti-sheep secondary antibodies were obtained from Abcam (Cambridge, MA). Sheep aE-selectin polyclonal antibodies were purchased from Leinco Technologies (St. Louis, MO). Dulbecco's phosphate buffered saline (PBS), $0.25 \%$ trypsin/2.6 mM EDTA, and Hoechst 33258 were obtained from Invitrogen (Carlsbad, CA).

\section{Liposome preparation}

Unilamellar liposomes were prepared by the extrusion method as previously described [13]. A mixture of DOPC:N-dod-PE (95:5 mol\%) in chloroform was dried in a rotary evaporator under reduced pressure. The lipids were then dissolved in a mixture of DMSO:EtOH (7:3 v/v). 
Lipid mixtures $(0.3 \mathrm{~mL})$ were injected in $3 \mathrm{~mL}$ PBS ( $\mathrm{pH}$ 7.4) with or without rhodamineconjugated dextran $(1 \mathrm{mg} / \mathrm{mL})$ while being agitated at $650 \mathrm{rpm}$ with a stir bar to yield $50 \mathrm{mM}$ lipid. The multilamellar vesicles were subjected to 10 freeze-thaw cycles (utilizing liquid nitrogen) prior to extrusion. Large unilamellar vesicles were prepared by utilizing a LIPEX ${ }^{\mathrm{TM}}$ extruder (Northern Lipids, Burnaby, Canada). Vesicles were extruded 10 times through a $200 \mathrm{~nm}$ polycarbonate membrane (Whatman Nucleopore $25 \mathrm{~mm}$ track-etched membranes, GE Healthcare Biosciences, Piscataway, NJ). Dextran-encapsulated liposomes were dialyzed against PBS using a Slide-A-Lyzer dialysis cassette (MWCO 20 kDa, Pierce Biotechnology, Inc., Rockford, IL) overnight at room temperature (RT). Liposome size was measured by dynamic light scattering on a ZetaPALS analyzer (Brookhaven Instruments, Corp., Holtsville, NY) in PBS ( $\mathrm{pH} 7.4)$.

The concentration of lipid in solution was determined by a phosphate assay as previously described [13]. Briefly, a diluted liposome sample was ashed with $0.2 \mathrm{~mL}$ sulfuric acid (10\% $\mathrm{v} / \mathrm{v})$ at $200^{\circ} \mathrm{C}$ for $1 \mathrm{~h}$, followed by addition of $50 \mu \mathrm{l}$ hydrogen peroxide (30\% v/v) and further heating at $200^{\circ} \mathrm{C}$ for $40 \mathrm{~min}$. After the sample was cooled down to RT, $480 \mathrm{~mL}$ deionized water and $0.5 \mathrm{~mL}$ of color reagent $(0.5 \% \mathrm{w} / \mathrm{v}$ ammonium molybdate, $2 \% \mathrm{w} / \mathrm{v}$ ascorbic acid) were added to each sample followed by heating at $45^{\circ} \mathrm{C}$ for $20 \mathrm{~min}$. The samples were read at $820 \mathrm{~nm}$ using a Spectramax Plus 384 spectrophotometer (Molecular Devices, Sunnyvale, CA). A calibration curve was prepared with known phosphate quantities.

\section{Preparation of antibody-labeled liposomes and microspheres}

Mouse aVCAM1 and mouse aE-selectin mAbs were conjugated to liposomes via the Ndod-PE anchor. EDC ( $2 \mathrm{mg}$ ) and NHS (3 mg) were added to $1 \mu \mathrm{mol}$ lipid (liposomes) in PBS 
(pH 7.4) and incubated for $6 \mathrm{~h}$ at RT. Excess EDC and NHS were removed using the Zeba Spin desalting column (MWCO $7 \mathrm{kDa}$, Pierce Biotechnology, Inc.). $\mathrm{IgG}_{1}$ isotype (100 mol\%, unspecific liposome) or mixtures of aVCAM1:aE-selectin (1:0, 1:1, 1:4, 1:8, 1:20, and 0:1 molar ratios) were added to EDC-modified liposomes at a molar ratio of 1:1000 antibody:phospholipids and incubated overnight at RT. Free antibodies were separated using a Sepharose CL-4B column (Fractionation range: 60-20,000 kDa, Sigma).

To determine the antibody density of aVCAM1 and aE-selectin on liposomes, 2-micron borosilicate beads (Duke Scientific, Palo Alto, CA), large enough to be detected by flow cytometry, were coated with a lipid bilayer. Microbeads and PC:N-dod-PE (95:5) liposomes were agitated in PBS for $6 \mathrm{~h}$. Microbeads coated with PC:N-dod-PE bilayers were washed 3 times with PBS through centrifugation-suspension cycles to separate free liposomes. In order to simultaneously label both aVCAM1 and aE-selectin, sheep aE-selectin antibodies were conjugated on microbeads instead of mouse aE-selectin antibodies. Conjugation of different ratios of aVCAM1:aE-selectin and control $\mathrm{IgG}$ (nonspecific binding) to microbeads was performed as described above using EDC/NHS chemistry. After free primary antibodies were separated, microbeads were conjugated with FITC-conjugated goat anti-mouse (aVCAM1 binding) and TRITC-conjugated rabbit anti-sheep (aE-selectin binding) secondary antibodies (10 $\mu \mathrm{l}, 10 \mathrm{ng} / \mathrm{mL}$ ) overnight at $4^{\circ} \mathrm{C}$. The secondary antibodies were separated using suspension-spin cycles. The density of aE-selectin and aVCAM1 conjugated to microbeads was determined with reference to Quantum ${ }^{\mathrm{TM}}$ Simply Cellular ${ }^{\circledR}$ anti-mouse $\mathrm{IgG}$ microbeads (Bangs Laboratory, Inc., Fishers, IN), which have defined numbers of antibody binding sites per bead. The microbeads were stained with FITC-conjugated mouse anti-rat secondary antibodies using the protocol provided by the manufacturer. 


\section{Cell culture}

Human umbilical vein endothelial cells (ECs) were grown in endothelial growth medium2 (EGM-2) with supplements as described by the distributor (Lonza, Allendale, NJ). Cells were maintained at $37^{\circ} \mathrm{C}$ in a humidified incubator with $5 \% \mathrm{CO}_{2}$ and used for experiments at passages 2-5. Growth medium was changed the day after cell seeding and every other day thereafter.

\section{VCAM1 and E-selectin immunostaining}

ECs $\left(2 \times 10^{5}\right.$ cells $)$ were seeded on $18 \times 18 \mathrm{~mm}^{2}$ coverslips in 6 -well plates with $2 \mathrm{~mL}$ media (VWR, West Chester, PA) and cultured overnight at $37^{\circ} \mathrm{C}$. Cells were incubated with IL$1 \alpha$ at $5 \mathrm{ng} / \mathrm{mL}$ or TNF- $\alpha$ at $20 \mathrm{ng} / \mathrm{mL}$ in fresh EGM- 2 media the next day for $6 \mathrm{~h}$ or $24 \mathrm{~h}$. After medium was removed, cells were rinsed with PBS three times and fixed with $4 \%$ formaldehyde in PBS at RT for 15 min followed by washing with PBS. Samples were blocked with $1 \%$ BSA in PBS (1\% BSA) at $4{ }^{\circ} \mathrm{C}$ for $1 \mathrm{~h}$. Samples were then stained with aVCAM1 and aE-selectin mAbs $(10 \mathrm{ng} / \mathrm{mL}$ in $1 \% \mathrm{BSA})$ at $4^{\circ} \mathrm{C}$ for $2 \mathrm{~h}$ and rinsed with PBS. Samples were incubated with FITCconjugated goat anti mouse (1:300), TRITC-conjugated rabbit anti-sheep secondary mAbs (1:300) and Hoescht $33258(1: 1000)$ at $4^{\circ} \mathrm{C}$ for $1 \mathrm{~h}$ followed by washing with PBS. Samples were then mounted on microscope slides (3"x1", VWR) with VECTASHIELD ${ }^{\circledR}$ mounting medium (Vector Laboratories, Burlingame, CA), and sealed. Samples were examined under an Axiovert 200 inverted fluorescent microscope (Carl Zeiss, Thornwood, NY) equipped with a Hammamatsu CCD camera (Bridgewater, NJ). Digital images were captured with AxioVision digital image processing software (Zeiss). 


\section{VCAM1 and E-selectin expression}

VCAM1 and E-selectin expression by ECs was evaluated by flow cytometry after 1, 6, 12, and $24 \mathrm{~h}$ incubations with either IL-1 $\alpha$ (5 ng/mL) or TNF- $\alpha(20 \mathrm{ng} / \mathrm{mL})$. Quantification of the density of molecules on the surface was determined using Quantum ${ }^{\mathrm{TM}}$ Simply Cellular ${ }^{\circledR}$ microbeads. After ECs were activated with IL- $1 \alpha$ or TNF- $\alpha, 10^{6}$ cells were collected from a 6well plate, spun down, and resuspended with ice cold 1\% BSA in PBS. ECs were rinsed 3 times through suspension-spin cycles and blocked with 1\% BSA in PBS for $30 \mathrm{~min}$ in an ice bath. ECs were incubated with mouse anti-human VCAM1 and sheep anti-human E-selectin mAbs (1 mL, $10 \mathrm{ng} / \mathrm{mL}$ ) for $30 \mathrm{~min}$ in an ice bath. After rinsing with $1 \%$ BSA in PBS 3 times to remove free mAbs, ECs were stained with FITC-conjugated goat anti-mouse and TRITC-conjugated rabbit anti-sheep secondary antibodies for $30 \mathrm{~min}$ in an ice bath. ECs were finally rinsed with $1 \% \mathrm{BSA}$ in PBS 3 times, resuspended in PBS, and analyzed by flow cytometry.

\section{Liposome uptake by ECs}

Liposome binding by ECs was analyzed using flow cytometry as previously described $[21,22]$. ECs were seeded in 6 -well plates $\left(3 \times 10^{5}\right.$ cells/well) and allowed to adhere overnight. After activation with IL- $1 \alpha$ or TNF- $\alpha$ for $6 \mathrm{~h}$ or $24 \mathrm{~h}$, ECs were incubated overnight at $37^{\circ} \mathrm{C}$ with: (1) dextran-loaded nonspecific $\left(\mathrm{IgG}_{1}\right)$ liposomes; and (2) dextran-loaded liposomes conjugated with different ratios of aVCAM1:aE-selectin mAbs. The concentration used was 1 $\mu \mathrm{mol}$ lipid $/ 10^{6}$ cells.

Treated ECs were washed with PBS, harvested using trypsin/EDTA solution, and collected in a polystyrene culture tube. Cells were washed with PBS three times. Liposomes were not detected by fluorescence in the trypsin solution used to remove ECs [17]. Binding data 
were acquired using an LSRII flow cytometry (BD Immunocytometry Systems, San Jose, CA) and analyzed with WEASEL software developed by WEHI (Parkville, Australia). The fold-over isotype value was calculated by dividing the mean fluorescence intensity for liposomes conjugated with aVCAM:aE-selectin by that of the isotype-conjugated liposomes. Significant differences in liposome uptake were evaluated using a 2-way ANOVA analysis. A P value less than 0.05 was considered statistically significant. 


\section{Results and Discussion \\ Characterization of liposomes}

Liposomes were prepared from $95 \mathrm{~mol} \%$ DOPC and $5 \mathrm{~mol} \% \mathrm{~N}$-dod-PE. The diameters of unconjugated DOPC:N-dod-PE liposomes were $205 \pm 5 \mathrm{~nm}$, as determined from dynamic light scattering. After conjugation with aVCAM1 and aE-selectin, liposome diameters increased to $223 \pm 3 \mathrm{~nm}$; the diameters were similar for all liposome formulations. The antibody density and aVCAM1:aE-selectin ratio were determined using standardized microbeads (Table 1). The average antibody density for 1:0 aVCAM:aE-selectin ratio was $6703 \pm 379$ molecules/ $\mu \mathrm{m}^{2}$ or $842 \pm 47$ molecules/liposome; this is comparable to other reports (7000 molecules/ $\mu \mathrm{m}^{2}$ [32], 4100 molecules $\left./ \mu \mathrm{m}^{2}[33]\right)$.

\section{VCAM1 and E-selectin changes temporally}

Inflammatory cytokines were used to upregulate the expression of VCAM1 and Eselectin on ECs as observed by immunostaining at 6 and $24 \mathrm{~h}$ (Figure 2). The surface expression of VCAM1 and E-selectin on TNF- $\alpha$ and IL-1 $\alpha$-activated ECs was quantified as a function of time (Figure 3). The expression of VCAM1 and E-selectin was affected by the duration of exposure, but not cytokine type (no statistical difference, $\mathrm{p}>0.05$ ). The density of E-selectin peaked at $6 \mathrm{~h}$ by ten-fold and nine-fold relative to unactivated ECs for both TNF- $\alpha$ and IL-1 $\alpha$, respectively. VCAM1 increased by three- and two-fold relative to expression on unactivated ECs after $24 \mathrm{~h}$ of exposure to TNF- $\alpha$ and IL-1 $\alpha$, respectively. The surface expression of VCAM1 and E-selectin on activated ECs was used to define a complementary antibody surface presentation on liposomes. 


\section{Complementary liposomes increase cellular binding}

Liposomes with different ratios of aVCAM1:aE-selectin were incubated with cytokineactivated ECs to observe the sensitivity of EC surface expression to liposome antibody presentation. ECs are known to transiently express VCAM1 and E-selectin in response to cytokines; this reproducible gene expression profile makes ECs a good model system for studying how changes in the EC surface presentation affects liposome targeting [23]. EC surface expression of VCAM1 and E-selectin was similar for IL- $1 \alpha$ and TNF- $\alpha$, approximately 1:20 and 1:1 VCAM1:E-selectin at 6 and $24 \mathrm{~h}$, respectively (Figure 3). EC binding of dextranencapsulating liposomes was evaluated by flow cytometry as a function of the aVCAM1:aEselection ratio (1:0, 1:1, 1:4, 1:8, and 0:1) and activation time (6 and $24 \mathrm{~h})$ (Figure 4A and 4B).

At early times, E-selectin is highly expressed in activated ECs; thus, liposomes presenting more aE-selectin exhibit greater binding. Liposome binding increased from 1.7-fold to 3.7-fold relative to $\mathrm{IgG}$ presenting liposomes, when the aVCAM1:aE-selectin ratio was reduced from 1:0 to 1:8 on TNF- $\alpha$ activated ECs, respectively. At later times, the increase in VCAM1 density on TNF- $\alpha$ activated ECs resulted in greater binding of liposomes with a comparable presentation of aVCAM1:aE-selectin. Liposome binding at $24 \mathrm{~h}$ peaked at 1:1 aVCAM1:aE-selectin; this was 2.3-fold greater than 1:0 and 0:1 aVCAM1:aE-selectin liposome formulations and $\sim 4$-fold greater than the IgG conjugated liposome control. Cellular binding at all non-optimal ratios were significantly lower than the 1:1 aVCAM1:aE-selectin liposomes ( $<<$ $0.001)$.

For TNF- $\alpha$, maximal binding was achieved when liposomes complemented the expression of VCAM1 and E-selectin on the EC surface; peak binding was observed at 1:8 and 1:1 aVCAM1:aE-selectin at 6 and $24 \mathrm{~h}$, respectively (Figure 4). This was analogous to the ratio 
of VCAM1:E-selectin expressed on the EC surface (Figure 3). No significant difference in binding was observed between the 1:20 and 0:1 aVCAM1:aE-selectin liposome formulation except for ECs activated for $24 \mathrm{~h}$ with TNF- $\alpha$ ( $\mathrm{p}<0.05)$ (Supplementary Figure 1A and 1B). Complementary liposomes had significantly higher binding than the 1:0 and 0:1 aVCAM1:aEselectin liposomes, confirming a cooperative interaction between colocalized VCAM1 and Eselectin [17].

Both TNF- $\alpha$ and IL-1 $\alpha$ activated ECs exhibited a $\sim 4$-fold increase in binding at $6 \mathrm{~h}$ for the 1:8 aVCAM1:aE-selectin liposomes. However, the 1:1 aVCAM1:aE-selectin liposomes exhibited maximal binding on IL-1 $\alpha$ activated ECs at both 6 and $24 \mathrm{~h}$. The inconsistency in binding may be a result of the organization of the VCAM1 and E-selectin on the surface. At $6 \mathrm{~h}$, E-selectin is observed predominantly in the perinuclear region in IL-1 $\alpha$ activated ECs, which does not consistently overlap with VCAM1 (Figure 2A). Although the average ratios of VCAM1:E-selectin are similar between TNF- $\alpha$ and IL-1 $\alpha$, the organization of the molecules may differ upon assembly within lipid rafts. We have previously reported that the organization of cell adhesion molecules within lipid rafts is critical for achieving cooperative binding of liposomes to activated ECs [17].

EC surface expression is used to regulate leukocyte-EC interactions $[2,26]$. E-selectin, whose expression is restricted on activated ECs, mediates the homing and rolling of leukocytes during the inflammatory response [27]. VCAM1 is virtually absent on normal endothelium; its expression is more widely expressed by cytokine-activated endothelial cells $[34,35$. Recently, VCAM1 expression has been shown to cluster primarily on the apical surface of ECs [23, 31]. The upregulation of VCAM1 and E-selectin is not enough to target inflamed ECs. The 
organization of the cell adhesion molecules is important in regulating liposome binding and cellcell interactions.

Our results suggest that liposomes, designed to be complementary to the activated EC surface at a particular time, may be optimized to deliver agents at specific stages of inflammation. Liposome binding is dependent on the density and organization expressed of molecules on ECs, which is regulated by the exposure time and type of cytokine.

In this report, we have demonstrated that liposomes with a complementary surface presentation to ECs resulted in increased binding relative to liposomes presenting either aVCAM1 or aE-selectin alone. Transiently-upregulated cell adhesion molecules may be exploited to design drug delivery vehicles that will have sustained binding to activated ECs.

\section{Conclusions}

Liposomes were targeted to IL- $1 \alpha$ and TNF- $\alpha$ activated ECs via cell adhesion molecules, VCAM1 and E-selectin, expressed transiently after cytokine stimulation. Maximal binding was achieved for TNF- $\alpha$ activated ECs when the ratio of aVCAM1:aE-selectin on the liposome surface was complementary to the VCAM1:E-selectin expression. However, the 1:1 aVCAM1:aE-selectin liposomes had maximal binding on ECs activated with IL-1 $\alpha$ at both 6 and $24 \mathrm{~h}$. The density and organization of cell adhesion molecules on activated ECs is important for cooperative binding. Efficient targeting may be achieved by understanding the transient expression, relative density, and organization of target EC surface molecules. 


\section{ACKNOWLEDGEMENT}

This project was supported in part by the Office of Naval Research (N000140710873), the

National Science Foundation (DMR-1055412), and the Ford Foundation Diversity Fellowship. 


\section{REFERENCES}

1. Kluger MS. Vascular endothelial cell adhesion and signaling during leukocyte recruitment. Adv Dermatol. 2004;20:163-201.

2. Siegel G, Malmsten M. The role of the endothelium in inflammation and tumor metastasis. Int J Microcirc Clin Exp. 1997;17:257-72.

3. Hussein MNA, Meesters EW, Osmanovic N, Romijn FPHTM, Nieuwland R, Sturk A. Antigenic characterization of endothelial cell-derived microparticles and their detection ex vivo. J Thromb Haemost. 2003;1:2434-43.

4. Okada M, Matsuto T, Miida T, Inano K. Differences in the effects of cytokines on the expression of adhesion molecules in endothelial cells. Ann Med Interne. 1997;148:125-9.

5. Lorenzon P, Vecile E, Nardon E, Ferrero E, Harlan JM, Tedesco F, et al. Endothelial cell E- and P-selectin and vascular cell adhesion molecule-1 function as signaling receptors. J Cell Biol. 1998;142:1381-91.

6. Wyble CW, Hynes KL, Kuchibhotla J, Marcus BC, Hallahan D, Gewertz BL. TNF-alpha and IL-1 upregulate membrane-bound and soluble E-selectin through a common pathway. J Surg Res. 1997;73:107-12.

7. Bloemen PGM, Henricks PAJ, van Bloois L, van den Tweel MC, Bloem AC, Nijkamp FP, et al. Adhesion molecules: a new target for immunoliposome-mediated drug delivery. FEBS Lett. 1995;357:140-4.

8. Murciano JC, Muro S, Koniaris L, Christofidou-Solomidou M, Harshaw DW, Albelda SM, et al. ICAM-directed vascular immunotargeting of anti-thrombic agents to the endothelial surface. Blood. 2003;101:3977-84.

9. Voinea M, Manduteanu I, Dragomir E, Capraru M, Simionescu M. Immunoliposomes directed toward VCAM-1 interact specifically with activated endothelial cells - A potential tool for specific drug delivery. Pharm Res. 2005;22(11):1906-17.

10. Ferrante EA, Pickard JE, Rychak J, Klibanov A, Ley K. Dual targeting improves microbubble contrast agent adhesion to VCAM-1 and P-selectin under flow. J Control Release. 2009;140:100-7.

11. Eniola AO, Hammer DA. In vitro characterization of leukocyte mimetic for targeting therapeutics to the endothelium using two receptors. Biomaterials. 2005;26:7136-44.

12. Eniola AO, Willcox JP, Hammer DA. Interplay between rolling and firm adhesion elucidated with a cell-free system engineered with two distinct receptor-ligand pairs. Biophys J. 2003;85:2720-31.

13. Gunawan RC, Auguste DT. The role of antibody synergy and membrane mobility in the vascular targeting of immunoliposomes. Biomaterials. 2010;31:900-7.

14. Tilghman RW, Hoover RL. E-selectin and ICAM-1 are incorporated into detergent-insoluble membrane domains following clustering in endothelial cells. FEBS Lett. 2002;525:83-7.

15. Kiely J-M, Hu Y, Garcia-Cardena G, Gimbrone J, - M. A. Lipid raft localization of cell surface E-selectin is required for ligation-induced activation of phospholipase $\mathrm{Cg}$. J Immunol. 2003;171:3216-24. 
16. Wang Q, Doerschuk CM. The signaling pathways induced by neutrophilendothelial cell adhesion. Antioxid Redox Signal. 2002;4:39-47.

17. Gunawan RC, Auguste DT. Immunoliposomes that target endothelium in vitro are dependent on lipid raft formation. Mol Pharm. 2010;7:1569-75.

18. Scholz D, Devaux B, Hirche A, Pötzsch B, Kropp B, Schaper W, et al. Expression of adhesion molecules is specific and time-dependent in cytokine-stimulated endothelial cells in culture. Cell Tissue Res. 1996;284:415-23.

19. Abid Hussein MN, Meesters EW, Osmanovic N, Romijn FP, Nieuwland R, Sturk A. Antigenic characterization of endothelial cell-derived microparticles and their detection ex vivo. J Thromb Haemost. 2003;1:2434-43.

20. Pober JS, Cotran RS. Cytokines and endothelial cell biology. Physiological Review. 1990;70:427-51.

21. Curtsinger JC, Deeths MJ, Pease P, Mescher MF. Artificial cell surface constructs for studying receptor-ligand contributions to lymphocyte activation. J Immunol Methods. 1997;209:47-57.

22. Marty C, Meylan C, Schott H, Ballmer-Hofer K, Schwendener RA. Enhanced heparan sulfate proteoglycan-mediated uptake of cell-penetrating peptide-modified liposomes. Cell Mol Life Sci. 2004;61:1785-94.

23. Alcaide P, Auerbach S, Luscinskas FW. Neutrophil recruitment under shear flow: it's all about endothelial cell rings and gaps. Microcirculation. 2009;16:43-57.

24. Parton RG, Richards AA. Lipid rafts and caveolae as portals for endocytosis: new insights and common mechanisms. Traffic. 2003;4:724-38.

25. Collinsa T, Palmera HJ, Whitleya MZ, Neisha AS, Williamsa AJ. A common theme in endothelial activation: Insights from the structural analysis of the genes for Eselectin and VCAM-1. Trends Cardiovasc Med. 1993;3:92-7.

26. Butcher EC. Leukocyte-endothelial cell recognition: three (or more) steps to specificity and diversity. Cell. 1991;67:1033-6.

27. Bevilacqua MP, Stengelin S, Gimbrone Jr. MA, Seed B. Endothelial leukocyte adhesion molecule 1: an inducible receptor for neutrophils related to complement regulatory proteins and lectins. Science. 1989;243:1160-5.

28. Kuzu I, Bicknell R, Fletcher C, Gatter K. Expression of adhesion molecules on the endothelium of normal tissue vessels and vascular tumors. Lab Invest. 1993;69:322-8. 29. Ryan D, Nuccie B, Abboud C, Winslow J. Vascular cell adhesion molecule-1 and the integrin VLA-4 mediate adhesion of human B cell precursors to cultured bone marrow adherent cells. J Clin Invest. 1991;88:995-1004.

30. Seron D, Cameron J, Haskard D. Expression of VCAM-1 in the normal and diseased kidney. Nephrol Dial Transplant. 1991;6:917-22.

31. Rice GE, Munro JM, Bevilacqua MP. Inducible cell adhesion molecule 110 (INCAM-110) is an endothelial receptor for lymphocytes. A CD11/CD18-independent adhesion mechanism. J Exp Med. 1990;171:1369-74.

32. Muro S, Dziubla T, Qiu W, Leferovich J, Cui X, Berk E, Muzykantov VR. Endothelial Targeting of High-Affinity Multivalent Polymer Nanocarriers Directed to Intercellular Adhesion Molecule 1. J Pharmacol Exp Ther. 2006;317:1161-1169.

33. Calderon AJ, Muzykantov V, Muro S, Eckmann DM. Flow dynamics, binding and detachment of spherical carriers targeted to ICAM-1 on endothelial cells. Biorheology. 2009; 46:323-341. 
34. Haraldsen G, Kvale D, Lien B, Farstad IN, Brandtzaeg P. Cytokine-Regulated Expression of E-Selectin, Intercellular Adhesion Molecule-1 (ICAM-7), and Vascular Cell Adhesion Molecule-1 (VCAM-1) in Human Intestinal Microvascular Endothelial Cells. J. Immunol. 1996;156:2558-2565.

35. Schnyder B, Lugli S, Feng N, Etter H, Lutz RA, Ryffel B, Sugamura K, Wunderli-Allenspach H, Moser R. Interleukin-4 (IL-4) and IL-13 bind to a shared heterodimeric complex on endothelial cells mediating vascular cell adhesion molecule-1 induction in the absence of the common gamma chain. Blood. 1996 87: 4286-4295.

36. Torchilin VP, Levchenko TS, Lukyanov AN, Khaw BA, Klibanov AL, Rammohan R, Samokhin GP, Whiteman KR. $p$-Nitrophenylcarbonyl-PEG-PE-liposomes: fast and simple attachment of specific ligands, including monoclonal antibodies, to distal ends of PEG chains via p-nitrophenylcarbonyl groups. Biochim. Biophys. Acta. 2001 1511: 397-411. 


\section{FIGURE CAPTIONS}

Figure 1. Schematic of immunoliposomal drug delivery vehicles targeting the transient expression of VCAM1 and Eselectin on ECs. VCAM1 and E-selectin are transiently expressed on ECs after activation with inflammatory cytokines TNF- $\alpha$ and IL-1 $\alpha$. E-selectin expression is instantaneous while VCAM1 is progressively expressed with time. Optimum binding of immunoliposomes can be continuously enhanced by complimenting the antibody surface presentation of aVCAM1 and aE-selectin to the VCAM1 and E-selectin expression on ECs over time $(\Delta \mathrm{t})$.

Figure 2. VCAM1, E-selectin, and $\operatorname{lgG}_{1}$ isotype control immunostaining for TNF- $\alpha$ and IL-1 $\alpha$-stimulated and unstimulated ECs. ECs were activated with TNF- $\alpha$ and IL-1 $\alpha$ for $6 \mathrm{~h}(\mathrm{~A})$ and $24 \mathrm{~h}(\mathrm{~B})$, then fixed, and immunostained with aVCAM1 and aE-selectin. After activation with either TNF- $\alpha$ or IL-1a, ECs transiently expressed VCAM1 and Eselectin. Scale bar, $10 \mu \mathrm{m}$.

Figure 3. Time-course expression of VCAM1 and E-selectin on TNF- $\alpha$ and IL-1 $\alpha$ activated ECs. ECs were activated with either TNF- $\alpha$ or IL-1 $\alpha$ for various durations. Expression of VCAM1 (A) and E-selectin (B) was determined using flow cytometry as a function of time. VCAM1 expression increased with time for up to $24 \mathrm{~h}$ while Eselection peaked at $6 \mathrm{~h}$ for both TNF- $\alpha$ and IL-1 $\alpha$.

Figure 4. Uptake of immunoliposomes conjugated with various ratios of aVCAM1 and aE-selectin by ECs. ECs activated with TNF- $\alpha$ and IL-1 $\alpha$ were treated with rhodamine-labeled dextran encapsulated in DOPC:N-dod-PE (95:5 mol:mol) for either $6 \mathrm{~h}(\mathrm{~A})$ or $24 \mathrm{~h}(\mathrm{~B})$. Flow cytometry was used to determine the cellular uptake of DOPC immunoliposomes conjugated with various ratios of aVCAM1:aE-selectin. Results are presented relative to uptake by lg $\mathrm{G}_{1}$-labeled liposomes (In (A) statistical significance was observed between TNF- $\alpha$ 1:4 and 1:8 aVCAM1:aE-selectin groups vs. all other TNF- $\alpha$ conditions and between IL1- $\alpha$ 1:1 aVCAM1:aE-selectin vs. all other IL1- $\alpha$ conditions. In (B) statistical significance was observed between TNF- $\alpha$ 1:1 aVCAM1:aE-selectin group vs. all other TNF- $\alpha$ conditions and between IL1- $\alpha$ 1:1 aVCAM1 :aE-selectin vs. all other IL1- $\alpha$ conditions. ${ }^{* * *} p<0.001$ as measured by 2 way ANOVA).

Supplementary Figure 1. Uptake of immunoliposomes conjugated with 1:20 and 0:1 ratios of aVCAM1 and aEselectin by ECs. ECs activated with TNF- $\alpha$ and IL-1 $\alpha$ for either $6 \mathrm{~h}(\mathrm{~A})$ or $24 \mathrm{~h}(\mathrm{~B})$ were treated with rhodaminelabeled dextran encapsulated in DOPC:N-dod-PE (95:5 mol:mol) . Results are presented relative to uptake by IgG ${ }_{1}$ labeled liposomes (* $p<0.05)$. 
Table 1. Antibody density and zeta potential of 95:5 DOPC:N-dod-PE immunoliposomes. All liposomes were assumed to have a surface area of $0.126 \mu \mathrm{m}^{2}$.

\begin{tabular}{cccc}
\hline $\begin{array}{c}\text { Ratio } \\
\text { aVCAM1:aE-selectin }\end{array}$ & $\begin{array}{c}\text { aVCAM1 } \\
\text { (molecules/liposome) }\end{array}$ & $\begin{array}{c}\text { aE-selectin } \\
\text { (molecules/liposome) }\end{array}$ & Zeta potential (mV) \\
\hline $1: 0$ & $842 \pm 47$ & - & $1.1 \pm 0.6$ \\
$1: 1$ & $571 \pm 30$ & $488 \pm 41$ & $-0.1 \pm 2.3$ \\
$1: 4$ & $215 \pm 19$ & $621 \pm 64$ & $0.9 \pm 0.6$ \\
$1: 8$ & $91 \pm 7$ & $623 \pm 54$ & $1.3 \pm 0.7$ \\
$0: 1$ & - & $849 \pm 89$ & $0.5 \pm 3.3$ \\
\hline
\end{tabular}




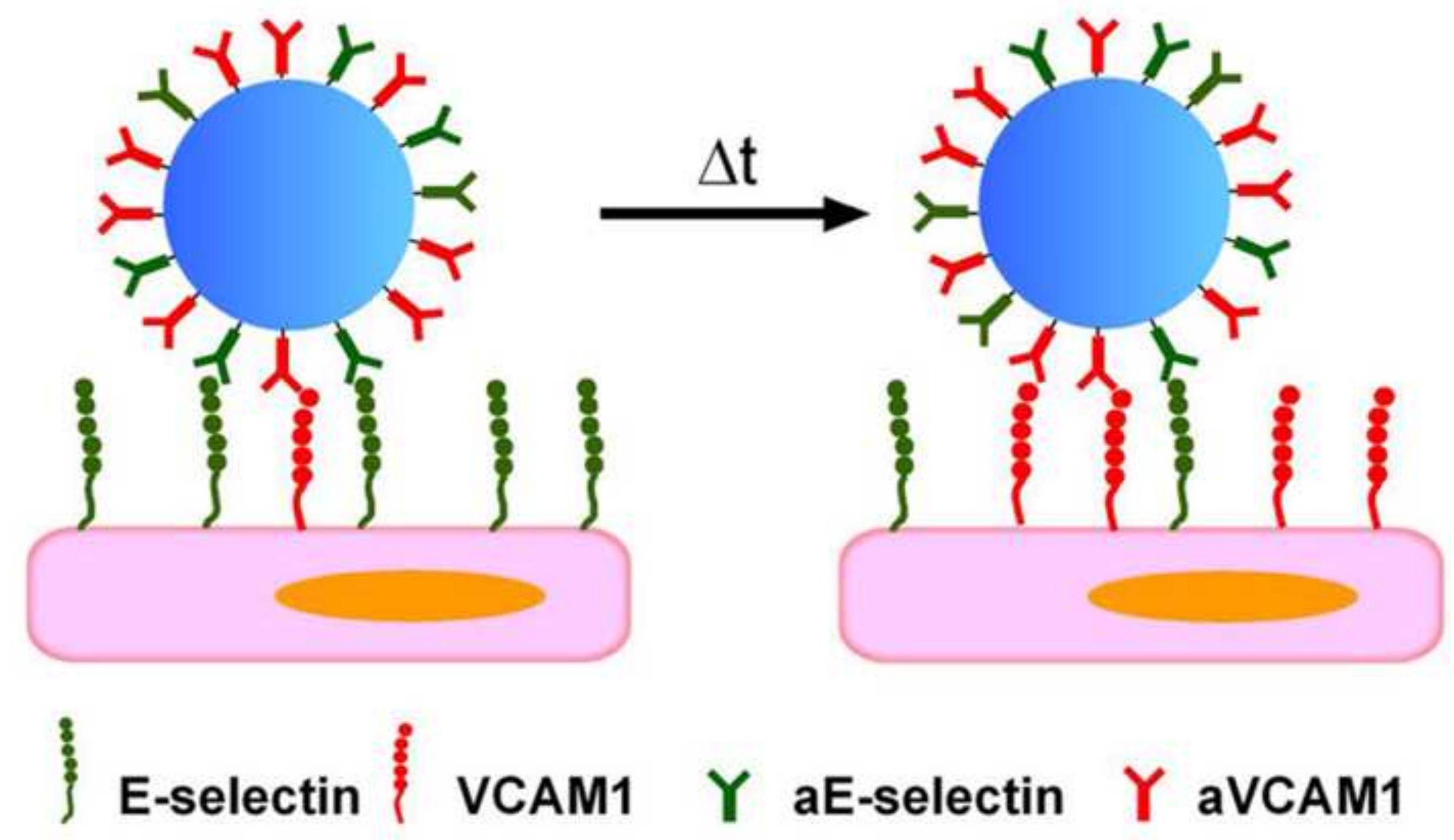




\section{Figure 2}

Click here to download high resolution image

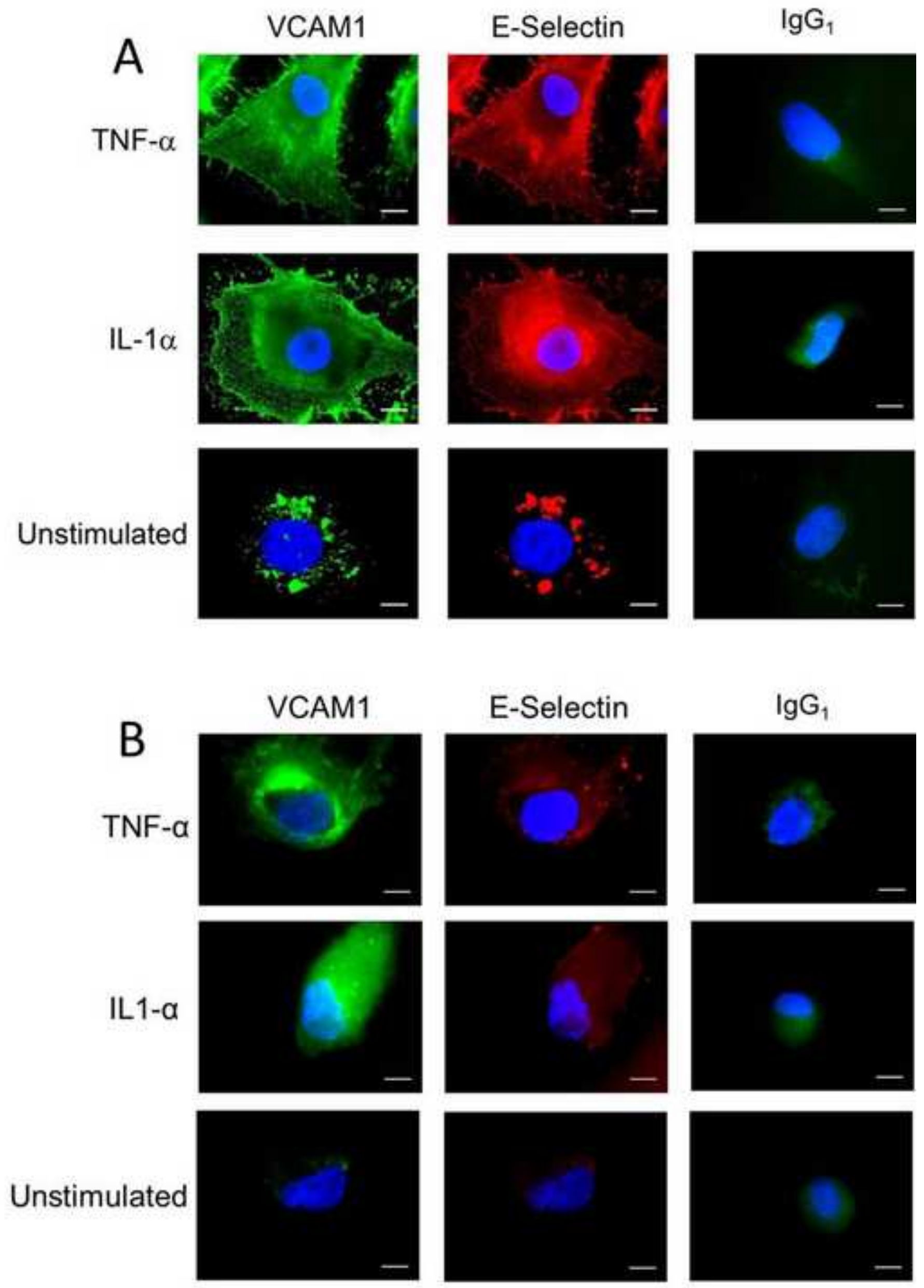



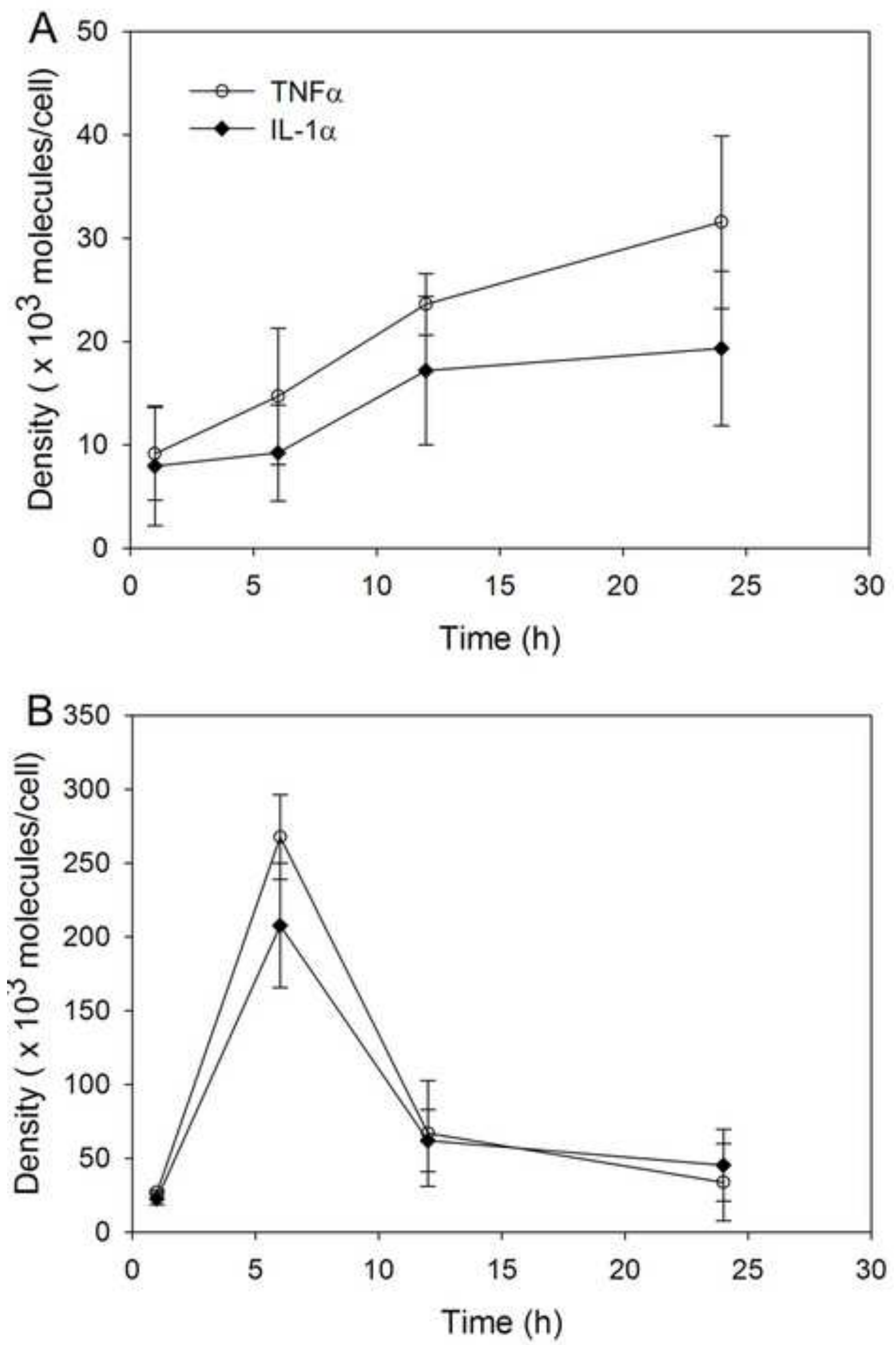
Figure 4

Click here to download high resolution image

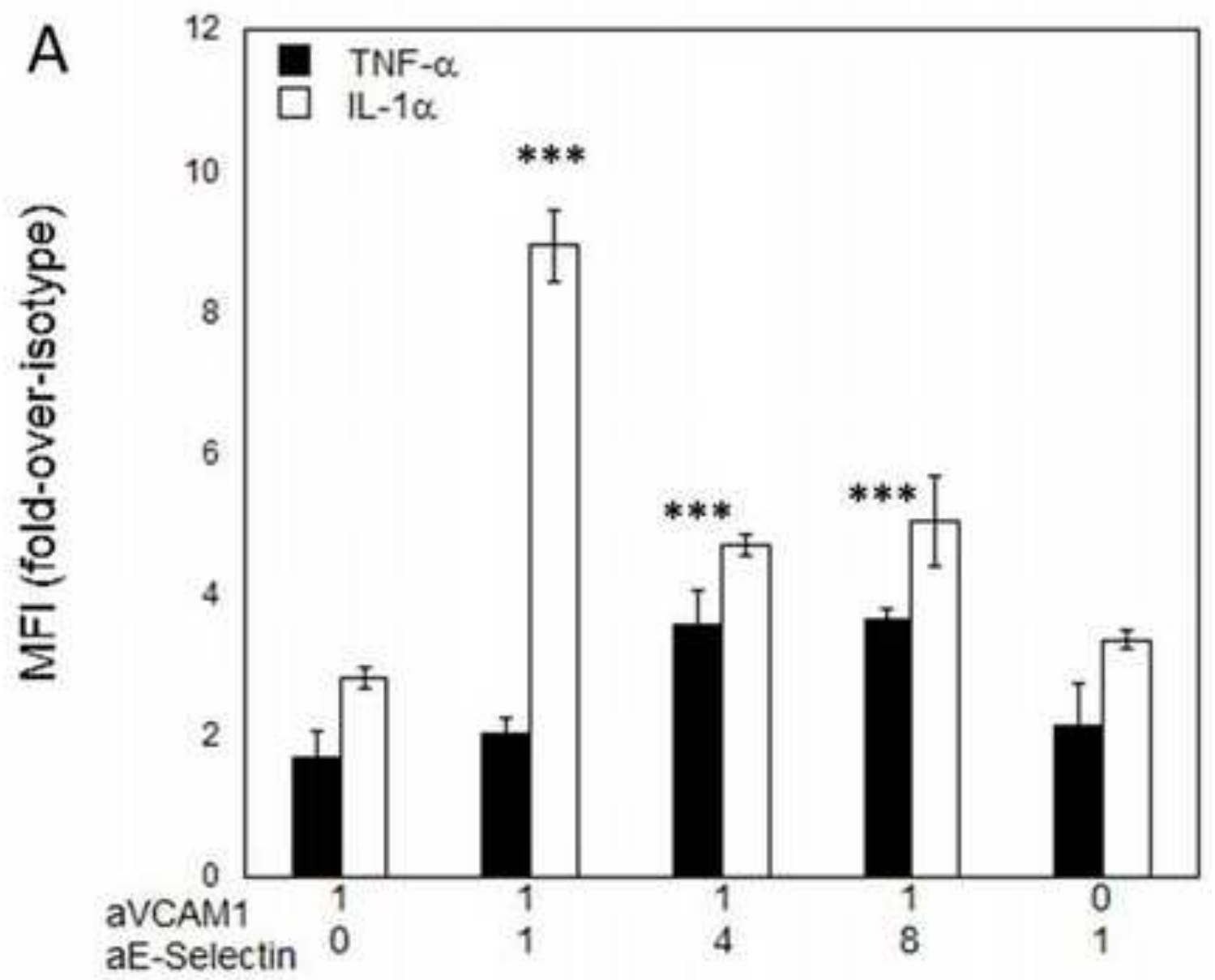

B

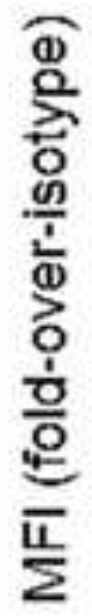

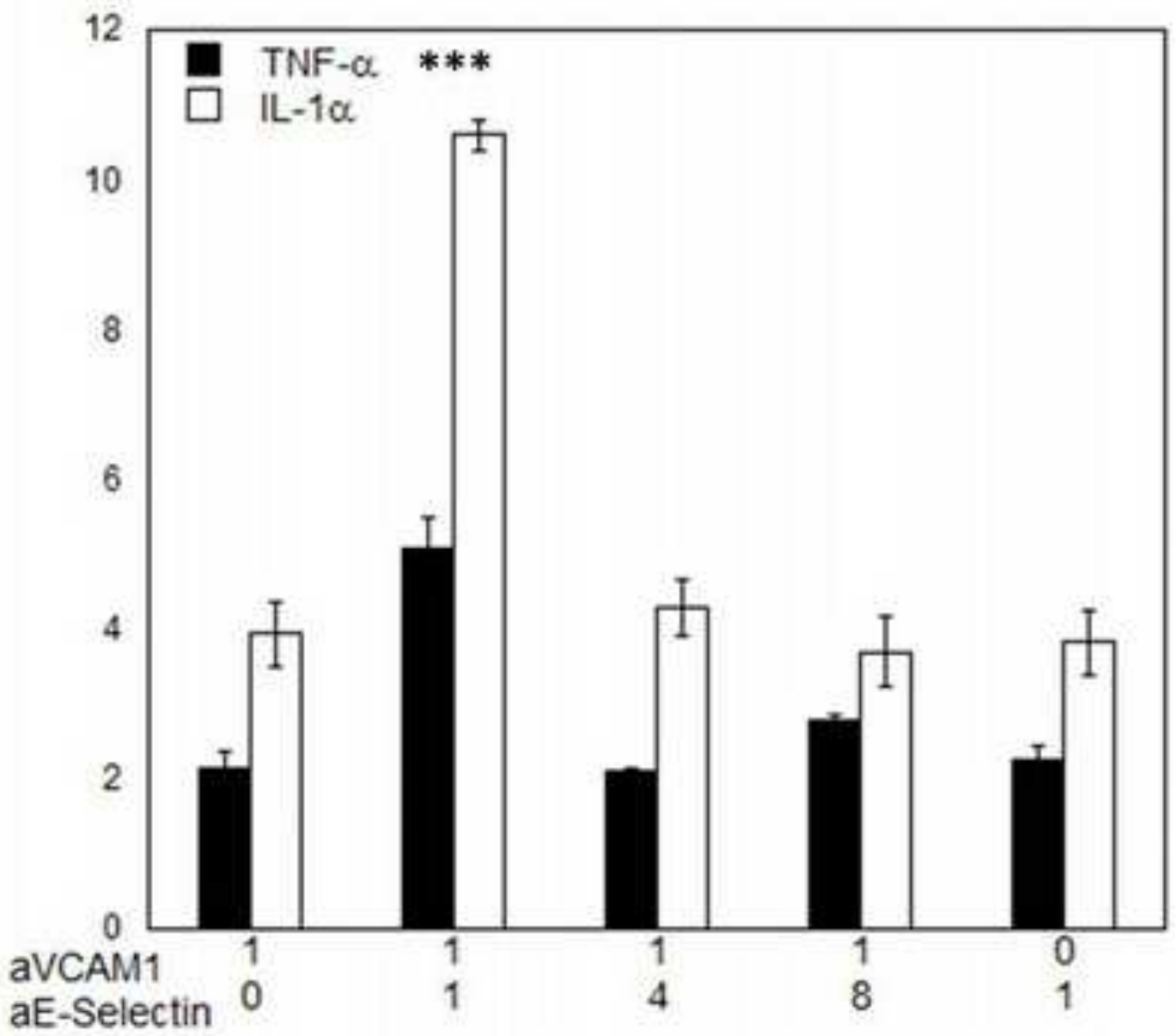



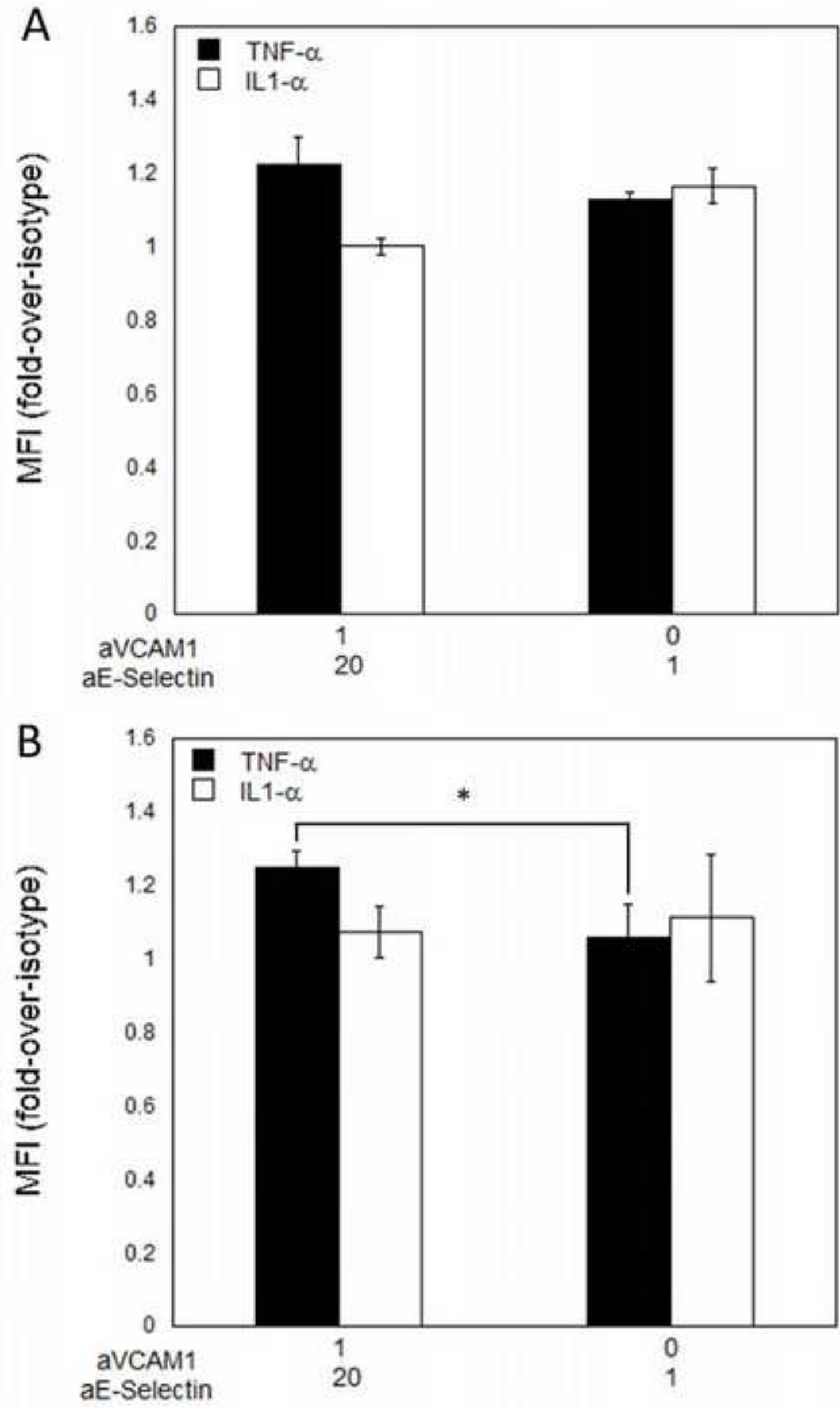